\title{
As crianças e suas brincadeiras em três nichos de formação: escola, mídia e instituições de acolhimento
}

\author{
Cleomar Ferreira Gomes ${ }^{1}$ \\ Raquel Firmino Magalhães Barbosa² \\ Sonia Cristina Oliveira ${ }^{3}$
}

\section{Resumo}

A proposta desse texto une três pesquisadores que propõem, a partir de suas pesquisas com crianças escolarizadas, uma reflexão sobre as implicações da rubrica lúdica nos espaços institucionais, não importando o grau, a série de estudo ou o tipo de formação, quando se percebe que o comportamento lúdico atravessa todos os estágios de hominização. Assim esses textos supõem conjugar uma empiria acadêmica, se orientando pelas lentes da corporeidade e da ludicidade, as quais costumam frequentar o espaço natural e cultural da formação escolar, seja pela via escolar, seja pela comunicação internetizada das mídias, seja pelas grades das instituições protetivas.

Palavras-chave: Comportamento Lúdico; Formação de Professores; Educação Escolar; Crianças Abrigadas; Infância Midiática.

\section{Children and their play in three training niches: school, media and host institutions}

\section{Abstract}

The proposal of this text unites three researchers who propose, from their research with schoolchildren, a reflection on the implications of the play line in institutional spaces, regardless of the grade, the study series or the type of formation, when one realizes that the playful behavior goes through all stages of hominization. Thus these texts imply to combine an academic empiricism, being guided by the lenses of corporeity and playfulness, which usually attend the natural and cultural space of the school formation, either by the school way, by the internet communication of the media, or by the grids of the protective institutions.

Keywords: Behavior Playful; Teacher Training; Schooling; Sheltered Children; Media Childhood.

\section{Introdução}

O labor pedagógico de todos os professores é suscitado pelas criações teórico-práticas, sem a carga da teoria sobre a prática e vice-versa, mas como forças inseparáveis de reflexão e ação. A primeira parte do texto é fruto de uma pesquisa com professores da rede municipal cuiabana sobre a importância dos jogos e das brincadeiras, que se supõe enxergar como estes irrigam a relação didática na formação de professores da Educação Infantil e do Ensino Fundamental.

\footnotetext{
${ }^{1}$ Professor Pesquisador Titular do Programa de Mestrado e Doutorado em Educação da Universidade Federal de Mato Grosso. Líder do Grupo de Estudos e Pesquisas sobre a Corporeidade e a Ludicidade - GPCOL, gomescleo.cg@gmail.com.

2 Professora Doutora do Colégio Pedro II, Campus Engenho Novo II, kekelfla@yahoo.com.br.

${ }^{3}$ Professora Doutora da Secretaria de Pública do Estado de Mato Grosso - SESP, oliveira.sonia@terra.com.br.
} 
O primeiro texto ${ }^{4}$ resume os encontros com os professores da rede municipal do ensino e aprendizagem da Educação Física em Cuiabá, Mato Grosso, numa pesquisa que tratou sobre a implicância dos jogos e das brincadeiras, supondo enxergar como estes desenvolvem a relação didática na formação de professores da Educação Infantil e do Ensino Fundamental.

Juntando-se a ele, a resenha de uma pesquisa de mestrado que intenta empreender, a partir da tríade infância, mídia e educação, uma aproximação do ambiente brincante infantil à criança e suas interações e, todavia, verifica o que compõem seus momentos lúdicos nas práticas brincantes com um renitente diálogo com as liturgias educativas da escola.

Na terceira via, onde se dá o carrefour desses trabalhos, imiscui-se o texto que tem como fito o brincar no lócus do abrigo, investigando se toda criança precisa brincar e quando brinca produz conteúdos relacionados a sua experiência de criança acolhida; se as brincadeiras têm determinações de aspectos sociais e culturais, e com quais referências imaginativas são marcadas com abandono, negligência e violência.

Tudo que escrevemos aqui sobre brincadeiras escolares, jogos, mídia, e instituição de acolhimento deve servir, se aceito como uma sugestão, para pensar o trabalho de todos nós no trato da educação escolar, mas que venha irrigar a formação de seus professores. Essa decisão se justifica considerando as fases de ensino: Educação Infantil ou primeira infância - até os cinco anos; Ensino Fundamental (primeiro ciclo) ou segunda infância - dos seis aos nove anos e Ensino fundamental (segundo ciclo) ou terceira infância - dos dez aos quatorze anos. Elas não são categorias fixas, mas postas assim como uma ferramenta que a própria categorização nos concede para expor um ponto de vista, isso não pode ser aceito como uma estrutura científica exata.

É temeroso dizer ao certo quando essas fases acontecem na vida das crianças. Tudo que os teóricos afirmaram em termos de fases, ciclos ou outra taxionomia foi a partir de aproximações científicas, sem o atestado exato do nascimento ou do óbito dessas fases. Há crianças em que os jogos e as brincadeiras sensório-motoras perduram e se misturam com a fase dos jogos simbólicos. Noutras, os jogos de construção ou de acoplagem invadem o tempo dos jogos com regras, que numa categoria piagetiana só chegaria à fase operacional concreta, isto é, depois dos sete anos.

\footnotetext{
${ }^{4} \mathrm{O}$ primeiro texto se inicia com o subtítulo "Brincadeiras na sociedade infantil" e vai até a página 7 , antecedendo a entrada do Homo zappiens, que é o resumo do segundo texto.
}

Periódico Horizontes - USF - Itatiba, SP - Brasil - e019052 
Antes mesmo de se pensar nas modalidades que esse conteúdo brincadeira evoca, pode se acatar a ideia primeira que tem alguns teóricos quando enxergam na brincadeira sua força propulsora para a criatividade infantil. Como acentua o psicanalista britânico Donald Winnicott (1975, p. 79): "é no brincar, e talvez apenas no brincar que a criança e ou o adulto fruem sua liberdade de criação".

Outros autores de matiz antropológico, como Roger Caillois (1990, p.59), nos advertem que a brincadeira não é simplesmente uma atividade de distração individual. É certo que há numerosos jogos de destreza em que requerem uma habilidade pessoal, mas mesmo essas brincadeiras perdem sua força quando praticadas sozinhas. No caso do ioiô, do pião, da pipa ou papagaio, a criança deixa logo de se divertir quando não há nem concorrentes e nem espectadores. O ser humano como um animal ritualístico carrega uma força intrínseca que faz o privado se exibir para o público. O que o autor sugere é que praticada solitariamente, logo a brincadeira deixa de ser uma atividade individual e passa a ser coletiva porque exige a presença do outro. É dessa lição educativa que podemos tirar proveito à formação de qualquer professor, quando se estiver no campo da Educação Infantil e do Ensino Fundamental.

Esse apelo do outro nos remete a novos desafios. Mais uma vez é esse mesmo autor que sugere que enxergamos uma fronteira entre as atividades lúdicas, do campo da paidia (palavra grega que se refere à criança), e às atividades regradas de ludus (palavra latina que quer dizer jogo com regras). Desse modo, quando as crianças se envolverem em atividades como a Amarelinha, Ciranda-Cirandinha, Mímicas, Parlendas etc., que têm uma função precípua de divertir ou de "matar o tempo da vida social" elas são enquadradas como Brincadeiras. Por outro lado, quando as atividades exigirem um apelo emocional, rigor intelectual e esforço físico de seus praticantes, a exemplo do Xadrez, da Queimada, do Bete ou Taco, dos videogames e das provas competitivas são chamados, então, de Jogos.

Esse "cruzamento semântico" sugere, de forma didática, uma compreensão para lidarmos no campo da escola com atividades que podemos utilizar a serviço da educação e da formação dos alunos - futuros professores - não importa o grau em que estejam. Se são preferencialmente lúdicas, divertidas e entretidas devem ser mais adequadas à Educação Infantil, sobretudo aquelas que lidam com brinquedos e com a fantasia das crianças. Esse campo simbólico infantil constitui uma fase fértil a explorar. 
Se forem atividades que exigem competitividade, aprendizagem de regras sociais e estímulo às condutas cooperativas, sugerimos que sejam destinadas às crianças mais graúdas, do Ensino fundamental. Para o Primeiro Ciclo $-1^{\circ}$ ao $5^{\circ}$ Ano, os Jogos que predisponham a entrada nalgum esporte, mas sem perder "a excelência do brincar", como insiste a pedagoga britânica Janet Moyles (2006), são bem-vindos. Para o Segundo Ciclo, do $6^{\circ}$ ao $9^{\circ}$ Ano, sugerimos os jogos que façam o aprendizado dos fundamentos esportivos, mas sem exigirem de seus praticantes a performance de um clube ou de uma "escolinha" esportiva.

\section{Brincadeiras na sociedade infantil}

As brincadeiras se situam, preferencialmente, no campo do simbólico, como diz Jean Château (1987) no terreno dos jogos de faz de conta. Elas nascem de uma força criativa que tem o ser humano, as crianças por excelência, para exercer a sua rubrica lúdica, isto é, a sua capacidade natural de inventar coisas, objetos, fatos e estórias que põem em ação para preencher o tempo de sua existência subjetiva e social.

Essas atividades devem ter a preocupação primordial de ajudar as crianças a se estimularem para sua criatividade, para a aprendizagem das regras sociais e para se libertarem dos "horrores do mundo de gigantes" como prefere o ensaísta alemão Walter Benjamin (1984, p. 64), porque esse mundo onde vive as crianças é feito de obrigações "pesadas" demais para a cultura infantil que tem outra realidade para dar conta. É bom lembrar que essa criança a que se refere o autor se materializaria numa "criança ideal" e não nas "crianças reais" que conhecemos, sobretudo aquelas dos países mais empobrecidos, onde têm, desde cedo roubado a sua infância.

É bom lembrar que o conceito brincadeira, com sua exibição semântica, não existe noutra cultura linguística, como nós a utilizamos por aqui. Muitas vezes se confunde com a palavra ludicidade que não consegue separar aquilo que dissimula, que simboliza e o que dá prazer. A qualidade que tem um objeto (brinquedo) ou uma atividade (brincadeira) que faz despertar um estado lúdico, a espontaneidade, o senso de humor e a alegria. É uma atividade livre, instável, voluntária e, não sujeita a ordens externas ao seio da própria brincadeira. O professor de crianças deve saber que é precisamente em tal fato que reside sua liberdade. 
Por que brincar é bom para as crianças?

As brincadeiras podem ser transmitidas de forma expressiva de uma geração a outra ou aprendida nos grupos infantis, na rua, em parques, escolas, igrejas, festas. Alguns autores, de corrente biológica afirmam que existe uma predisposição genética: basta nascer e já se sabe brincar. O enigma de Kaspar Hauser ${ }^{5}$ pode servir de exemplo. Incorporada pelas crianças de maneira espontânea varia nas regras e na organização do conteúdo, segundo as convenções da própria cultura infantil. Pode acontecer de uma brincadeira ter um nome diferente, constituir-se de número distinto de brincadores, muda a forma, mas mantém o mesmo conteúdo e função. A bola de gude serve de exemplo que em algumas regiões do Brasil chama-se "birosca", "bolita" ou "burquinha". Em alguns lugares faz um círculo para prender as "bolitas', noutro faz-se um triângulo, noutros não faz figura nenhuma.

Desse modo toda brincadeira pode ser identificada a partir de seu conteúdo que se expressa em relação aos seus objetivos de envolver os brincadores e fazer chegar até o fim; a sua forma que indica a organização da atividade no que se refere aos objetos, tempo, espaço e número de brincadores e sua função precípua: a de entreter os seus participantes. Quando essas atividades ou conteúdos, intencionalmente, adquirem status pedagógico para ensinar alguma coisa aos seus brincadores, eles viram jogos. Isto é, atinge o estágio de jogo.

$\mathrm{Na}$ brincadeira, por redundância da aliteração, o participante aprende a brincar a brincadeira, descobre os seus mecanismos de execução, se torna um habilidoso, como manipular um pião, um bilboquê, pular uma corda ou saltar os quadrados da Amarelinha. Esse movimento é espontâneo e o brincador aprende a operar. A brincadeira pode ser aprendida, isto é, servir de conteúdo, quando ao mesmo tempo pode servir de ferramenta, fazendo a vez de método - uma maneira global de expressão, comunicação e exploração do mundo infantil que envolve todos os domínios de sua natureza.

Nos jogos, há uma intenção anunciada, quando se aprende alguma coisa com o que se joga. Alguma coisa externa à própria dinâmica do jogo, exemplo, quando o jogador aprende a

\footnotetext{
${ }^{5}$ O Enigma de Kaspar Hauser é um filme alemão ocidental de 1974, um dos mais celebrados do diretor Werner Herzog. O filme inicia mostrando um jovem acorrentado em um porão, alimentado por um homem misterioso. $O$ prisioneiro brinca com um cavalo de madeira, e o nome do objeto é a única palavra que pronuncia: cavalo. Disponível em: http://pt.wikipedia.org/wiki/o enigma de Kaspar Hauser. Acesso em: 15 set. 2014.
}

Periódico Horizontes - USF - Itatiba, SP - Brasil - e019052 
cooperar (literalmente a operar com o outro), a perder, a vencer, a conhecer as regras do Jogo ${ }^{6}$ : aprende sobre operações matemáticas e regras da gramática. As mnemônias (técnicas para desenvolver a memória e memorizar coisas, que utiliza exercícios e ensina artifícios, como associação de ideias ou fatos difíceis de reter, a fazer combinações e arranjos de elementos numéricos) são um bom exemplo para guardar datas, valores, e identificar famílias das espécies.

\section{Sugestões de atividades para crianças até cinco anos}

As crianças que pertencem a esse grupo costumam a repetir todo o tipo de movimento que Ihes dão prazer. Mas como os movimentos são feitos de modo sincrético essas atividades aparecem como os primeiros exercícios sensoriais simples ou combinações de ações sem finalidade aparente. Puxar um carrinho, fazer rodar um arco, tentar fazer sair um som, bater um tantã, arremessar um objeto... são gestos que se prolongam até a vida adulta, mas nessa fase implicam em poucas aquisições novas porque não requerem aquela complexidade, por isso eles tendem a abandonar rapidamente e diminuir a intensidade porque não fazem chegar ao seu fim.

A recomendação é para que nessa fase envolvermos as crianças em brincadeiras ou atividades lúdicas leves e moderadas, que dispensem a aceleração e a precisão dos movimentos. Como não dominam uma precisa coordenação motora, tendem a se debaterem e a se machucarem nesses eventos. As brincadeiras cantadas, as brincadeiras de roda, a manipulação de brinquedos simples e as estórias fabulosas exercitam a fantasia, que divulguem o simulacro e o faz de conta são muito bem-vindas.

Nas brincadeiras simbólicas as crianças aprendem a fazer imitações, a brincar de faz de conta, a incorporar o "Era uma vez..." a representar os pais, o seu professor, sujeitos importantes em processo de sublimação. Os eventos imaginários envolvem em situações distintas do mundo dos adultos, como no caso da boneca que faz as meninas articularem personagens, acessórios e condutas desse mundo. Nas brincadeiras de construção ou de acoplagem as crianças vão

\footnotetext{
${ }^{6} \mathrm{O}$ vocábulo jogo, no singular será usado aqui como uma expressão fenomênica da corporeidade humana como assevera Konrad Lorenz e dos animais, como afirma Karl Groos em sua obra the play of animals. Quando usarmos jogos no plural será uma designação genérica referente às atividades recreativas, escolares, divertidas e de entretenimento, bem como fazem as brincadeiras de crianças.
}

Periódico Horizontes - USF - Itatiba, SP - Brasil - e019052 
aprender sobre ordenamentos lógicos. É quando os objetos se juntam para formar um carro, um barco, uma casa. Outra etapa desta fase, que começa mais ou menos aos quatro anos de idade, mas ainda de modo confuso são as atividades lúdicas com regras simples que vão se complexando até os sete anos.

\section{A trajetória da infância à chegada do homo zappiens: novos rumos para a escola}

Esta segunda parte resenha uma pesquisa de mestrado (BARBOSA, 2011) que intenta empreender, a partir da tríade infância, mídia e educação, uma aproximação do ambiente brincante infantil, à criança e suas interações e, todavia, verifica o que compõem seus momentos lúdicos nas práticas brincantes com um renitente diálogo com as liturgias educativas da escola.

Dialogar sobre a infância, especialmente a sua trajetória, é uma maneira de pensarmos sobre como essas mudanças são capazes de influenciar as crianças de hoje, e como a escola se comporta neste cenário. Partindo desse ponto, nos mantemos nas perspectivas teóricas de Ariès (2006), de Colin Heywood (2004), de Zygmunt Bauman (2010; 2011) e de Veen e Vrakking (2009), com os quais se produz um encaminhamento sobre a construção sociocultural da infância e a sua relação com a educação, trazendo algumas considerações sobre o contexto histórico da infância da Idade Média até o momento contemporâneo, com o objetivo de compreender a relação da geração zapping com a instituição escolar e como esta pode se aproveitar deste movimento.

Durante a Idade Média, o conhecimento sobre a infância não existia porque havia um total desconhecimento do significado de ser criança, isto é, não tinham descoberto o sentiment de l'enfance. Para Heywood (2004, p. 33) é uma expressão ambígua que transmite tanto a ideia de uma consciência de infância quanto de um sentimento em relação a ela - nada que distinguisse a criança do adulto. Não existia um período transitório da passagem da infância à idade adulta e não havia consciência dessa etapa da vida.

Durante o século XIII até o século XV, percebeu-se uma grande influência religiosa e a mudança na percepção da infância, influenciado diretamente pela devoção da imagem do Menino Jesus, apresentando uma maneira de se exaltar a infância (HEYWOOD, 2004). Neste momento, o brincar aparece como uma conduta típica da infância, que segundo Tizuko 
Kishimoto (1999), assumiu um aspecto de espontaneidade, liberdade e prazer, comparando a criança à alma de um poeta.

A partir do século $\mathrm{XV}$, o sentimento e a figura da criança começaram realmente a ser notados, sobretudo, devido às descobertas sobre a graça, a alegria, os hábitos e as falas enquanto eram pequeninas, em suas primeiras brincadeiras, "[...] ao tratar as crianças como uma fonte de prazer e relaxamento, deleitando-se com sua doçura, sua simplicidade e seus gracejos" (HEYWOOD, 2004, p. 33).

Mas somente, a partir do século XVII, que lançaram um olhar mais educativo para a criança, utilizaram a escolarização e o emprego de jogos educativos como instrumento rico para o processo de ensino-aprendizagem e para o desenvolvimento das crianças, principalmente, para contrabalancear o ensino com a palmatória, ensinando valores e comportamentos, favorecendo a aprendizagem por meio de jogos e brincadeiras.

Os movimentos da Escola Nova do início do século XX proporcionou que a criança fosse vista de forma ativa e com seus traços e comportamentos lúdicos, e também a brincadeira com todo o seu arcabouço livre, espontâneo e autotélico (KISHIMOTO, 1999).

Embora os esforços para se estudar a infância tenham ganhado força a partir do século XIX e XX, ainda persistiam ideias sobre a criança como um ser incompleto, com o pressuposto que a idade adulta era a fase fundamental da vida e que a infância era apenas uma preparação, ou seja, prolongou-se, por muitos anos, a infância como algo natural, influenciado diretamente pelo aspecto biológico e não como uma construção social que se transforma ao longo do tempo.

A partir de todos esses elementos que influenciaram a trajetória da infância, chegamos ao período contemporâneo, com uma preocupação em pensar sobre as crianças e a sua educação, de modo que, "[...] a criança de hoje tem a chave para o reino de amanhã"7 (HEYWOOD, 2004, p. 44).

Com a fase industrial e o progresso pelo qual o mundo passou e está passando e assistindo a evolução tecnológica a cada dia e cada vez mais perto, a criança na sociedade de hoje consome informações e imagens, passa por mudanças diárias e se adapta a todos os artefatos dessa nova era, isto é, "[...] não perde de vista as formas mutantes de infância como

\footnotetext{
7 Palavras de um jornal britânico de 1910, "The Child Welfare Annual", p. vii, citado por Woolridge, Measuring the Mind (HEYWOOD, 2004, p.44).
}

Periódico Horizontes - USF - Itatiba, SP - Brasil - e019052 
constructo social" (HEYWOOD, 2004, p. 45).

Assim, surge uma nova geração, capaz de lidar com a tecnologia de forma natural e com o aprendizado rápido. São indivíduos que transparecem tranquilidade frente às transformações que surgem a cada dia e usam a tecnologia ao seu favor, conseguindo se adequar facilmente a sociedade contemporânea, pois nasceram, cresceram e descobriram o mundo através da tela da TV, do videogame, do computador, dos celulares e dos tablets. E em meio a essa grande mistura de capacidades, nasceu o homo zappiens, com a capacidade de estar "antenado", revelando-se um ser tecnologizado (VEEN; VRAKKING, 2009).

Logo, o homo zappiens está sempre cercado por muitos recursos tecnológicos e midiáticos, se mostrando sempre atualizado com o que está acontecendo e com o que supri suas necessidades. Essa realidade é visualizada facilmente quando se observa uma criança brincando, vendo TV e conversando espontaneamente sobre todos os produtos relativos aos seus desenhos animados e filmes favoritos, ou seja, "[...] o homo zappiens é um processador ativo de informação, resolve problemas de maneira muito hábil, usando estratégias de jogo, e sabe se comunicar muito bem" (VEEN; VRAKKING, 2009, p. 12).

Nota-se que dentro deste cenário a aprendizagem é algo que necessita de constantes atualizações, visto que as informações surgem com muita rapidez. Não se pode negar que vivemos em um mundo de consumo, de fruição instantânea, e fica bem mais inteirado aquele que dispõem de recursos tecnológicos ao menor alcance. Nesta direção, a discussão nos conduzirá à metáfora da velocidade dos processos na sociedade "líquido moderna" desenhada pelo sociólogo anglo-polonês, Zygmunt Bauman (2011). Sairá na frente quem puder transformar informação em conhecimento, utilizando de tecnologia.

\section{Quais lições à formação dos professores?}

Em tempos de mudança, percebemos que a utilização da tecnologia é algo inevitável. Alguns produtos high tech deixam as nossas vidas mais fáceis, tornando o mundo algo mais próximo. Isso faz parte do nosso cotidiano e que se mantém disponível a todo o momento, construindo e reconstruindo a vida de adultos e de crianças. Observando pelo aspecto da infância, percebemos que há uma forte tendência de as crianças se apegarem a esse universo 
tecnológico, entretanto, temos que considerar esse novo olhar, fazendo conviverem o homo ludens e o homo zappiens com ajustes no modelo de escola a nossa disposição.

As brincadeiras e os brinquedos que as crianças trazem para a escola acabam causando uma sensação de insegurança nos professores, em não saber como trabalhar com essas novas mudanças, como exemplo, temos as alterações na estrutura e nos nomes das brincadeiras, bem como, o acréscimo de personagens, de estratégias e de regras dentro dos jogos ${ }^{8}$. Por isso, a necessidade de interagirmos com elas, tentar observar essa geração zapping, que traz objetos, informações e comportamentos novos para escola, compartilha com outras crianças e que deveriam ser conhecidas e pesquisadas pelos professores. Seguindo esta lógica: “[...] a lição que temos de aprender é a de sermos criativos e ignorarmos obstáculos" (VEEN; VRAKKING, 2009, p.25). Supomos aqui, ser um grande desafio para a escola nesse período "líquido moderno" em “[...] lidar com o tempo e com a incerteza, com a mudança e o desenvolvimento que está se tornando a atividade mais valorizada: essa atividade é a aprendizagem" (VEEN; VRAKKING, 2009, p.24).

É impossível não se ater e não se preocupar com essa revolução na educação, que "mexe" com os ânimos dos educadores. É uma massa enorme de informação, que provoca uma verdadeira desordem e caos e essa mesma massa chega e flui com a mesma intensidade. Podemos nos esquivar, porém, ela pode nos tocar e nos deixar desacordados. Para Bauman (2011, p. 125), o papel da educação esbarra "na arte mais difícil e fascinante de preparar seres humanos para essa vida". Bauman (2011, p. 125) assevera que a educação, por ter que assumir "muitas formas" teve que se "adaptar às mudanças das circunstâncias, definir novos projetos, elaborar novas estratégias". Ele arremata dizendo que "em nenhum momento crucial da história da humanidade os educadores enfrentam desafio comparável ao divisor de águas que hoje nos é apresentado. [...] Aprender a arte de viver num mundo saturado de informações". (BAUMAN, 2011, p. 125).

A chegada do homo zappiens trouxe mal-estar e uma série de complicações para a estrutura da "escola conservadora", que por séculos permaneceu sem nenhuma ou com pouca alteração em seu cotidiano. "[...] Ao que parece, a velocidade de mudança agora governa as

\footnotetext{
${ }^{8}$ Estudo desenvolvido na dissertação intitulada "Um estudo sobre a cultura lúdica infantil e o desenho animado", orientada pelo Prof. Doutor Cleomar Ferreira Gomes, com o objetivo de conhecer as brincadeiras realizadas pelos alunos nos espaços brincantes e escolares e registrar a influência e o significado dos desenhos animados no imaginário infantil (BARBOSA, 2011).
}

Periódico Horizontes - USF - Itatiba, SP - Brasil - e019052 
condições em que vivemos, com pessoas em permanente e acelerado movimento" (BAUMAN, 2010, p.154). Isso acabará configurando uma situação inevitável: se deixarmos que o aspecto "conservador" continue prevalecendo sem interagir com as crianças e com o mundo fora das escolas, é provável que continuemos sem saber lidar com a geração zapping.

Em contrapartida, o desafio está lançado: a inserção do homo zappiens na escola é uma forma dos professores buscarem a capacidade e a perspicácia de mediar às informações trazidas pelas crianças, a simplicidade para aprender com elas, ao mesmo tempo, que compartilham o conhecimento, e, acima de tudo, a consideração em levar em conta os pontos de vista e a maneira de ver o mundo delas, de modo a criar um misto de reflexão e significação no processo de ensino e aprendizagem.

\section{Brincadeiras em instituição de acolhimento: lições à ludicidade com crianças abrigadas}

A terceira parte do texto tem como fito o brincar no lócus do abrigo, investigando se toda criança precisa brincar e quando brinca produz conteúdos relacionados a sua experiência de criança aprisionada; se as brincadeiras têm determinações de aspectos sociais e culturais, com quais referências imaginativas que são marcadas com abandono, negligência e violência.

Este loci de pesquisa toma como participantes as crianças institucionalizadas, portadores de uma urgência para que seus direitos sejam cumpridos e sua permanência na instituição seja compreendida como um direito adquirido, uma vez que não podem contar como um privilégio.

A discussão teórica sobre infância foca seus princípios na Sociologia da Infância - SI, com autores como Sarmento (2003), Corsaro (2011), Prout (2010), Qvortrup (2011) e outros. A SI tem grifado, nos últimos tempos, que as crianças são atores sociais porque interagem com as pessoas, com as instituições e reagem frente aos adultos quando desenvolvem estratégias de luta para participar no mundo social. No entanto o modelo de infância prevista na SI ainda não encontrou vez e voz nas instituições. Estas com a ideologia de cuidar, proteger e socializar em pleno século XXI aprisionou a criança em casa, na escola e nas instituições jurídicas. As escolas possuem muros cada vez mais altos para sua segurança e dos alunos, em detrimento de parques, brinquedos e espaços para brincadeiras; a justiça aprisiona para proteger, e o que parece proteção acaba virando privação. 
Historicamente, conforme Nascimento, Lacaz e Filho (2010) dois momentos são importantes antes da promulgação do Estatuto da Criança e do Adolescente (ECA) em 1990. Primeiro, o Código Mello Mattos no 17.943-A, de 1927, lei que delineia os critérios de atendimento e cuidados da infância. Esse decreto era conhecido como o que vigorou no país durante 52 anos, passou por algumas alterações, porém sem ser modificado em seu caráter higienista e repressor, sendo característica importante à higienização da sociedade. A proposta não derruiu os muros de muitos abrigos de acolhimento, dos quais convivem com práticas e ações similares aos orfanatos/instituições de atendimento em grande escala. O segundo foi o Código de Menores de 1979 que estabelecia novas medidas de proteção ao menor de idade, ampliou poderes para autoridades judiciárias com o intento de atender os desvalidos, infratores e abandonados, buscando meios de corrigir as supostas causas dos desajustamentos sociais dessas crianças, e neste momento surgiram os menores em situação irregular.

Com advento do ECA, crianças e adolescentes passam a ser considerados como sujeitos de direitos, não sendo mais consideradas objetos de proteção, ou seja, não mais como menores a disposição da ação do poder público, em casos de abandono e/ou delinquência, passíveis de medidas assistencialistas, segregadoras e repressivas como previa nos Códigos de Menores de 1927 e 1979. O ECA propõe que as crianças e adolescentes, antes vistas como portadores de carências ou irregulares sejam cidadãos, portanto, sujeitos de direitos.

Quando nos encontramos com palavras "iluminadas", como estas letras da lei, salta a esperança de que podemos encontrar a criança pensada na Sociologia da Infância, doravante protegidas que estão no interior das instituições, conforme já dito, crianças vistas como sujeitos sociais que interagem com as pessoas, instituições e com os adultos desenvolvem estratégias e participam no mundo social. Uma vez que as crianças participam coletivamente da sociedade e são dela personagens ativos e não meramente expectadores, são atores sociais, que adquirem voz e são credoras de direito. O certo é que as leis não protegem as crianças no seu todo, porque as pessoas que cuidam ainda carecem de muita formação para interpretar e usar a lei a favor da criança abrigada.

Mediante estas considerações teóricas, a pesquisa teve por finalidade investigar o brincar no contexto de abrigo, e saber como as brincadeiras, se ajustam ou integram como um instrumento de acolhimento, desenvolvimento e de aprendizagens para a vida social das 
crianças. A ideia central, perseguida na investigação, incide em questões de pesquisa com as seguintes proposituras: 1) se toda criança tem que brincar e quando brinca traz conteúdos relacionados a sua experiência? 2) Como essa criança "aprisionada" organiza e vivencia essa experiência lúdica? 3) Se as brincadeiras têm determinações de aspectos sociais e culturais e com quais referências usam o imaginário nas brincadeiras, uma vez que são marcadas pelo abandono, negligência e violência?

\section{Da pesquisa feita}

A pesquisa é um estudo de caso do tipo etnográfico que tomou como local uma instituição de acolhimento em Cuiabá/MT que abriga e protege crianças de até 12 anos, vítimas de algum tipo de negligência/violência familiar encaminhadas pela justiça por serem abandonadas ou sofreram maus tratos. Para a coleta dos dados, foi usada observação em situações de brincadeiras livres e sugeridas pela recreadora com um grupo de crianças de 2 a 6 anos de meninas e meninos. Os nomes foram omitidos nos episódios, mesmo sendo uma pesquisa que procura dar visibilidade e voz às crianças, neste caso foi acordado que não seriam identificadas porque estão sob a custódia do Estado.

As crianças foram observadas em grupos, apenas pela pesquisadora, que, mantendo uma "proximidade etnográfica" (tomamos aqui como a expressão pensada por nós, aquela do tamanho exato que não se imiscui na ação, mas que assegura o registro dos dados ou "sinais" propostos pelo "paradigma indiciário", tão usual às pesquisas deste gênero), filmou e fez registros em diário de campo das brincadeiras. Há vários episódios registrados, mas para este trabalho elegemos apenas um.

\section{Episódio 01 - A casinha de mato}

As crianças foram brincar no campo de futebol. Algumas brincaram com areia, de casinha em vários grupos separados. Os meninos juntaram-se num grupo e foram brincar sozinhos, fizeram uma casinha de mato (como se fosse uma oca). Ao mesmo tempo brincavam de carrinhos de faz de conta em torno da casinha. Quando aproximei um menino veio correndo me apresentar à casinha, e disse: mora nesta casa eu, meu pai e um tio. [...]. Um menino entrou na casinha e disse, vou dormir aqui. Outros dois meninos disseram: vou fazer bolo. Outro 
reclamou, ele não quer deixar eu trabalhar, e apontou para o colega. Este que foi apontado respondeu: eu deixei, deixei ele brincar. Depois disse: tia, nós tá trabalhando de casinha. Um outro garoto fingiu ir embora com carrinho e disse andando de quatro pés, empurrando seu carrinho no chão: eu vou embora, tchau e saiu. No caminho tinha um monte de areia, fingiu que era um quebramolas, fez força, subiu o carro e passou. Os que estavam fazendo bolo vieram me oferecer: tia quer bolo? O outro que passou o quebra-molas, disse: vou passar neste caminho estranho, fingindo que estava numa estrada perigosa. Depois fizeram uma festa de aniversário e me convidaram, me ofereceram bolo, sorvete, doces.

Este episódio é representado por meninos que brincam de casinha e fazem atividades domésticas, mas não há a figura de mãe entre os meninos, embora façam bolo e comida. E nas meninas não há pai, entretanto, a figura de mãe é muito forte. O simulacro de dormir, se faz presente em todos os episódios que pudemos registrar.

A dissimulação do mundo do faz de conta e dos jogos dramáticos pode emprestar às crianças a possibilidade de imitar o mundo dos adultos, interpretando o meio em que vivem, reelaborando situações desconfortáveis, sociabilizando e desenvolvendo a linguagem verbal, a criatividade e os pré-requisitos para o conhecimento sistematizado (BARBOSA, 2006). A brincadeira de faz de conta imprime significados aos objetos, simula ser outro personagem ou cria contextos imaginários. É uma atividade que ocorre interações, resolução de conflitos, assume papéis e distintos significados.

Arrematando com Sarmento (2003, p. 14) as crianças desenvolvem a sua imaginação a partir do que observam, experimentam, ouvem e interpretam da sua experiência, concomitante, as situações que imaginam lhes permitem compreender o que observam, interpretando situações e experiências de modo fantasista, até incorporarem como experiência vivida e interpretada.

\section{Considerações finais}

Que lições educativas as crianças e seus professores podem ter com as brincadeiras os jogos na escola? Com a evolução da tecnologia e a sendentarismo do homem, conforme decreta Le Breton (2003, p. 21): "a humanidade passou a ser uma humanidade sentada”, cada vez mais 
é urgente estimular o movimento corporal através de jogos e de brincadeiras nos loci escolares. A passagem da criança, da educação infantil ao ensino fundamental, é preenchida com brincadeiras, jogos e o movimento farto, mas que ainda ficam restritos às aulas de educação física. Se o professor adotar brincadeiras em suas aulas, quando sozinhas, nos encontros fugidios entre uma aula e outra ou ao recreio, elas vão reproduzir esse movimento adotado pelos professores. Esse mesmo movimento pode ser adotado na sala de aula, a partir daquela fase de ler e escrever como conteúdos de pauta para a ascensão do sujeito.

As virtudes que sucedem com a adoção da brincadeira no design escolar e seu enfrentamento com a formação total das crianças podem favorecer às crianças: identificar, classificar, agrupar, ordenar, seriar, simbolizar, combinar, estimar, e ao mesmo tempo, desenvolver a atenção, a concentração, a socialização, o fair play, sem mesmo a interferência do adulto. A brincadeira é por si só estimuladora na aquisição de algum conhecimento. A percepção daquilo que consideramos como espaço "sagrado", enquanto instituições de ensino, é que cada vez mais a brincadeira, o jogo - o lúdico, enquanto rubrica do Homo ludens, assim como o movimento corporal estão privados do processo de aprendizagem.

As instituições escolares e de acolhimento devem fazer parte deste projeto, por compreender através de estudos que as necessidades infantis, no que se refere a processos de formação e desenvolvimento, em relação ao mundo que a cerca, deve interagir com outros sujeitos, com o brinquedo e ainda entendendo a criança como um ser lúdico, criativo, curioso.

As crianças dos episódios mostrados na instituição de acolhimento representam nas brincadeiras um cenário de famílias, das quais nem sempre fazem parte de sua experiência de vida, mas é possível justificar a posição de que mesmo a criança que não vive em sua família de origem pode estabelecer, a partir da brincadeira, alguns padrões de interação que dão conta de representar aquilo que para ela tem significado, deseja ou se realiza no imaginário, o modelo de família que ela aspira ou rejeita. Afinal de contas há no espectro de toda brincadeira um arrebatamento que a criança tenta realizar no seu mundo lúdico, mesmo que esse jogo proporciona a fuga do real, encantamento ou evasão.

As crianças que vivem nos abrigos de acolhimento, vítimas de abandono, negligência, violência física e psicológica quando vão para a escola e ao final do dia não possuem um vínculo afetivo para receber e levar para casa, vivem sob a tensão da possibilidade de adoção ou retorno 
para família. Vivem num lar - que na verdade é uma instituição com normas rígidas para obter o controle num espaço físico com muitas crianças. Seus cuidadores têm vínculos profissionais, em detrimento das crianças que têm desejos de serem amadas e acolhidas verdadeiramente, sentir que é alguém único e importante. Não seria demasiado dizer que neste contexto em particular, quanto mais as crianças brincam, mais se evidencia a alegria em sua vida social. Percebemos que quando a brincadeira se torna "vigiada" demais, as crianças que a ela se dedicam perdem a graça e o interesse espontâneo, sentimentos próprios do estado puro da brincadeira.

Por meio dos paradigmas apontados, percebemos que a infância apresentou diferentes características de acordo com a sociedade, o contexto social e o período histórico vigente. Assim, este ensaio apresentou a trajetória da infância e da brincadeira com diferentes facetas ao longo dos séculos, desde a ausência do sentiment de l'enfance no período da Idade Média até a chegada do homo zappiens, nessa fase contemporânea.

É esse conjunto de ações que faz dessa trajetória e transformação social da infância, uma maneira de vermos tanto a criança como a brincadeira com um olhar mais apurado, "[...] a infância tem formas próprias de ver, pensar, sentir, e, particularmente, sua própria forma de raciocínio, sensível, pueril, diferentemente da razão intelectual ou humana do adulto" 9 (HEYWOOD, 2004, p.38), possuindo uma natureza única, sua própria visão de mundo e fortalecendo o seu zeitgeist.

Por isso, a necessidade de conhecer a história da infância para entender a geração zapping e como a escola pode interagir e intervir nesse processo. Faz-se necessário que o mundo dentro da escola converse com a realidade fora da escola, no sentido de gerar um aprendizado exógeno, que provém do exterior. E quando os professores perceberem, já estarão embebidos nessa nova realidade, e a curiosidade, a vontade de aprender e de se atualizar os farão conhecer esse novo mundo - o grande desconhecido -, territórios talvez nunca antes visitados.

A intenção é nos aproximarmos do mundo que nos rodeia, contudo, esse universo é

\footnotetext{
${ }^{9}$ Heywood (2004) destaca que as crianças têm suas especificidades e aponta que a noção de infância de Jean Jacques Rousseau nos mostrar a importância de nos esforçarmos para compreender as crianças em seus próprios jeitos e em suas brincadeiras, sem impor as vontades dos adultos. Isto é, devemos buscar considerar seus desejos e o que trazem dos seus cotidianos brincantes.
}

Periódico Horizontes - USF - Itatiba, SP - Brasil - e019052 
repleto de incertezas, de fluidez, de neblina e de mistérios. Esse mundo desconhecido em que a escola, o processo de ensino-aprendizagem e alguns professores ainda estão inseridos, é ambíguo, isto é, ao mesmo tempo que se torna ameaçador também desperta curiosidade, especialmente, para aqueles que sentem necessidade de se aventurar por esse novo caminho.

Para esses aventureiros, que buscam novas e contínuas formas de aprendizado, entrarão em um mundo novo e constantemente atualizado, e não terão como voltar para a caverna aludindo à alegoria platônica -, pois estarão em uma fase de descobertas, reflexões e experiências, que ficarão arraigadas em seu ser. E ainda, poderão contagiar outros sujeitos, apresentando novos conceitos e ideias, dentro de um processo cíclico por meio da educação. Com isso, poderão se livrar das correntes e dos paradigmas pré-estabelecidos que os prendem dentro da caverna. Aparentemente haverá uma sensação de ofuscamento ao sair dela, mas logo conseguirão ver um mundo rico em possibilidades de ensino e de aprendizagem.

Nesta perspectiva, os professores devem valorizar a aprendizagem e o que a enriquece. Basta que nos conformemos com uma realidade que não mais existe e tenhamos curiosidade, vontade, empenho e criatividade para encarar esse novo mundo e todas as mudanças que vem com ele, a fim de nos aproximarmos o máximo possível do "estado da arte" e conhecermos o mundo fora da caverna.

Os trabalhos revelam que no dia a dia dessas instituições, a ludicidade, enquanto uma linguagem do corpo, interpretada como estorvo aos ritos do ensinar, do acautelar e do aprender, ainda vigem como expressão de comunicação social entre crianças e jovens.

\section{Referências}

ARIÈS, P. História social da criança e da família. 2. ed. Rio de Janeiro: LTC, 2006.

BARBOSA, L. M. S. A educação de crianças pequenas. São José dos Campos: Pulso, 2006.

BAUMAN, Z. 44 cartas do mundo líquido moderno. Rio de Janeiro: Zahar, 2011.

BAUMAN, Z. Aprendendo a pensar com a sociologia. Rio de Janeiro: Zahar, 2010.

BENJAMIN, W. Reflexões: a criança, o brinquedo, a educação. São Paulo: Summus, 1984.

CAILLOIS, R. Os jogos e os homens: a máscara e a vertigem. Lisboa: Cotovia, 1990. 
CHÂTEAU, J. O jogo e a criança. São Paulo: Summus, 1987.

CORSARO, W. Sociologia da infância. Trad. L. G. R. Reis. Porto Alegre: Artmed, 2011.

GROOS, Karl. The play of animals. New York: D. Appleton and Company, 1898.

HEYWOOD, C. Uma história da infância: da Idade Média à época contemporânea no Ocidente. Porto Alegre: Artmed, 2004.

KISHIMOTO, T. M. Jogo, brinquedo, brincadeira e a educação. São Paulo: Cortez, 1999.

LE BRETON, D. Adeus ao corpo. Campinas: Papirus, 2003.

LORENZ, Konrad. Os fundamentos da Etologia. São Paulo: Editora da Unesp, 1995.

MOYLES, J. R. A excelência do brincar. Porto Alegre: Artmed, 2006.

NASCIMENTO, M. L.; LACAZ, A. S; FILHO. J. R. A. Entre efeitos e produções: ECA, abrigos e subjetividades. Barbarói. Santa Cruz do Sul, n.33, p. 50-64, ago./dez. 2010..

PROUT, A. Reconsiderando a nova sociologia da infância In: Cadernos de Pesquisa. Trad. F. Murad. São Paulo, v. 40, n. 141, p. 729-750, set/dez, 2010.

QVORTRUP, J. Infância como um fenômeno social. Trad. M. L. Nascimento. Pro-Posições, Campinas, v. 22, n.1, p.199-211, jan./abr, 2011.

SARMENTO, M. J.; GOUVEA, M. C. S. (orgs.). As culturas da infância nas encruzilhadas da 2aa . modernidade. In: SARMENTO, M. J.; CERISARA, A. B. (Orgs.). Crianças e miúdos, perspectivas sociopedagógicas da infância e educação. Porto: ASA, 2003, p. 9-34. Braga, Portugal. Universidade do Minho. Centro de Estudos da Criança, 2002 (mimeo.). Disponível: http://cedic.iec.uminho.pt/textos_de_trabalho/textos/encruzilhadas.pdf. Acesso em 10 de abril 2012.

VEEN, W.; VRAKKING, B. Homo zappiens: educando na era digital. Trad. V. Figueira. Porto Alegre: Artmed, 2009.

WINNICOTT, D. W. O brincar e a realidade. Rio de Janeiro: Imago, 1975.

Recebido em novembro de 2017.

Aprovado em maio de 2019. 